\title{
Research on Construction Crack Diagnosis and Treatment Technology of Double-Column Large Cantilever Pre-Stressed Bent Cap
}

\author{
Runjian Wang ${ }^{1}$ \\ ${ }^{1}$ Beijing Gongke Solid Bridge Technology Co., Ltd, Beijing, China
}

\begin{abstract}
This paper took a pre-stressed bent cap of a high pier of a bridge as the research object, expounded the crack type and construction process of the bent cap, combined with the numerical calculation and analysis of the construction process to study the crack generation mechanism and its influence during the construction period of the bent cap. Besides, it gave the repair and treatment technology of jacking and unloading combined with pressure glue, so as to provide reference for the disease diagnosis and treatment of similar bridge structures.
\end{abstract}

\section{Introduction}

As a beam set on the top of the pier and abutment, the bent cap transfers the dead load and live load of the bridge superstructure transmitted from the bearing to the substructure, it is an important force-bearing component of the bridge structure. Its force characteristics are not only affected by the bridge span, bridge width, main girder structure form, load level and other factors, but also related to the supporting conditions and construction technology. However, due to design and construction reasons, the bent cap will crack during construction. After the bent cap is cracked, the internal force of the cross section is redistributed, the area of the concrete in the compression zone of the cracked section is reduced, the shear resistance section is reduced, stress concentration is formed, resulting in stress concentration and greater loss of bearing capacity. After being put into operation, the live load may lead to further increase of crack development, aggravation of crack degree and even damage. Therefore, it is necessary to analyze and study the causes of cracks in the construction period of bent cap, provide accurate data for the treatment of the bent cap cracking disease, and verify the rationality of the bent cap design.

Taking the cracks in the negative bending moment area of a T-beam bridge's double-column cantilever pre-stressed bent cap during construction as an example, this paper analyzes the mechanism of the cracks in the bent cap, and the feasibility and effectiveness of adopting the jacking and unloading combined with pressure glue repair scheme.

\section{Bridge Overview}

The superstructure form of the bridge is: 18-holes 40-meters precast pre-stressed T-shaped beam, with the bridge span layout: $3 \times 40+5 \times 40+3 \times 40+4 \times 40+3 \times 40 \mathrm{~m}$, one 160-type expansion joint is set at bridge pier No.3, No.8, No.11 and No.15, and one 80-type expansion joint is set at abutment No.0 and No.18. The height of 3 \# - 9 \#, 11 \#, 14 \# bridge piers is more than $40 \mathrm{~m}$, the height of the bent cap on pier top is $2.00 \mathrm{~m}$, the width is $2.35 \mathrm{~m}$, the cantilever on both sides is $5.11 \sim 5.19 \mathrm{~m}$, the pre-stressed layout of bent cap is 5 holes, each hole has 25 steel strands, the layout of pre-stressed steel tendon is shown in Figure 1, and the detail of steel tendon is shown in Table 1.

Table 1 List of bent cap steel tendon

\begin{tabular}{|c|c|c|c|c|c|c|c|c|c|}
\hline \multirow[b]{2}{*}{$\begin{array}{c}\text { Serial } \\
\text { No. }\end{array}$} & \multirow[b]{2}{*}{$\begin{array}{l}\text { Steel tendon } \\
\text { type } \\
\text { (piece / } \\
\text { bundle) }\end{array}$} & \multirow[b]{2}{*}{$\begin{array}{l}\text { Cutting } \\
\text { length of } \\
\text { single } \\
\text { steel } \\
\text { tendon } \\
(\mathrm{cm})\end{array}$} & \multirow[b]{2}{*}{$\begin{array}{c}\text { Weight } \\
\text { of a bent } \\
\text { cap steel } \\
\text { tendon } \\
(\mathrm{kg})\end{array}$} & \multicolumn{2}{|c|}{ A bent cap plastic bellows } & \multicolumn{2}{|c|}{ Anchorage } & \multirow[b]{2}{*}{$\begin{array}{l}\text { Tension } \\
\text { control force } \\
\text { KN/bundle }\end{array}$} & \multirow[b]{2}{*}{$\begin{array}{c}\text { Extension } \\
\text { amount } \\
\mathrm{cm}\end{array}$} \\
\hline & & & & $\begin{array}{c}\text { Inner } \\
\text { diameter / } \\
\text { wall } \\
\text { thickness } \\
(\mathrm{mm})\end{array}$ & $\begin{array}{l}\text { Number of roots } \\
\mathrm{x} \text { length of single } \\
\text { root }(\mathrm{cm})\end{array}$ & Specifications & Qty (set) & & \\
\hline N1 & $25 \mathrm{ss}^{\mathrm{s}} 152$ & \multirow{4}{*}{1674} & \multirow{4}{*}{2304} & \multirow{2}{*}{$115 / 3$} & \multirow{2}{*}{$2 \times 1569=3138$} & $15-25$ & 2 & \multirow{2}{*}{4883} & \multirow{4}{*}{11.2} \\
\hline NI & $25 \varphi 15.2$ & & & & & $15-25 \mathrm{P}$ & 2 & & \\
\hline \multirow{2}{*}{$\mathrm{N} 2$} & \multirow{2}{*}{$25 \varphi^{\mathrm{s}} 15.2$} & & & \multirow{2}{*}{$115 / 3$} & \multirow{2}{*}{$3 \times 1569=4707$} & $15-25$ & 3 & \multirow{2}{*}{4883} & \\
\hline & & & & & & $15-25 \mathrm{P}$ & 3 & & \\
\hline
\end{tabular}




\section{Cracking of bent cap and its cons- truction technology}

\subsection{Bent cap cracking during construction}

The nine bent cap with the pier height greater than $40 \mathrm{~m}$ all had cracks from the installation and erection process of the T-beam to the second pre-stressed steel tendon tensioning. The cracks were distributed at the root of the bent cap cantilever and extend from both sides to the top surface, the length of cracks on the sides of high and low pile numbers is different. The serious cracks are in double "L" shape and extend downward to the position of $20 \mathrm{~cm} \sim 30 \mathrm{~cm}$ from the bottom surface of bent cap, but none of them reach the bottom surface. The cracks are wide in the middle of the side of the bent cap, and narrow in the top and end of the side cracks. The cracks are wide in the middle and thin at both ends. The maximum width of the side cracks is $1.42 \mathrm{~mm}$, and the maximum width of the top cracks is $0.53 \mathrm{~mm}$. The schematic diagram of cracks in the 9\# bent cap is shown in Figure 1.

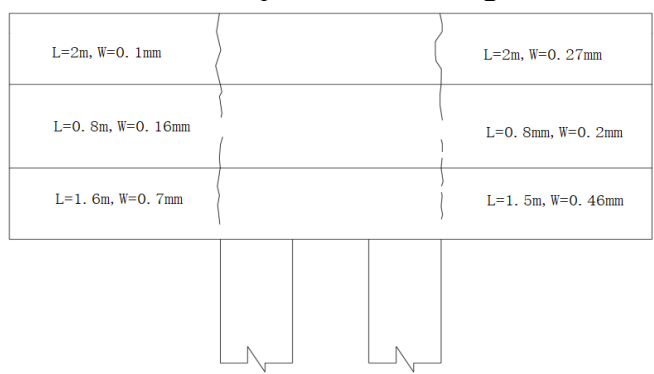

Figure 1 Crack diagram of $9 \#$ bent cap (Unit: $\mathrm{m}$ )

From the photos of $9 \#$ bent cap cross seam drilling core sample (Figure 2) and the cross seam section after $11 \#$ bent cap removal (Figure 3), it can be seen that the side cracks of $11 \#$ bent cap high and low pile number almost run through the entire section; The coring length of 9 \# bent cap is $37 \mathrm{~cm}$, and the crack is still extending inward. Due to the limitation of the detection method, the specific information of the crack depth cannot be given, but the crack depth of the bent cap can be judged to be deeper.

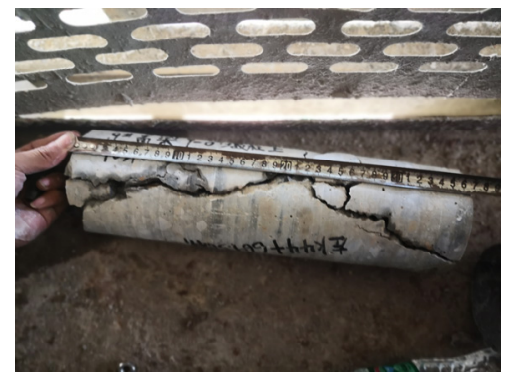

Figure 2 Photo of cracks in 9\# bent cap

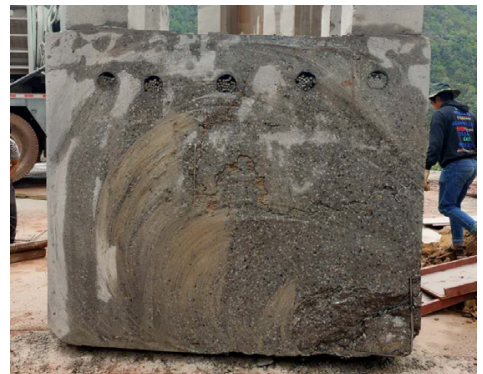

Figure 3 Cross-section photo of 11\# bent cap cut across seam

\subsection{Construction technology of bent cap}

The bent cap construction shall be carried out according to the following procedures: installation of construction platform $\rightarrow$ installation of formwork and reinforcement $\rightarrow$ concrete pouring (due to the $4 \%$ cross slope, in order to prevent concrete segregation, the pouring sequence is first in the middle, and then from the low slope to the high slope, pouring in layers) $\rightarrow$ curing of bent cap concrete $\rightarrow$ tensioning the first batch of steel tendon of bent cap $\rightarrow$ removing the bent cap support and formwork $\rightarrow$ hoisting the prefabricated T-beams (all T-beams on the bent cap) $\rightarrow$ tensioning the second batch of steel tendon of bent cap $\rightarrow$ cast-in-place bridge deck and construction of bridge deck system.

(1) During the first pre-stressed tensioning, the strength of bent cap concrete shall reach $100 \%$ and the curing time shall not be less than 14 days. Two N1 steel tendon shall be tensioned in three grades of $0-15 \%-50 \%$ - $100 \%$, and finally be supplemented to $103 \%$.

(2) The precast T-shape beams are lifted symmetrically, and the installation sequence is from the inside to the outside.

(3) The second batch of N2 steel tendons are tensioned after the installation of all T-beams on the bent cap and before the pouring of $10 \mathrm{~cm}$ bridge deck concrete. When the N2 steel tendons are tensioned, the middle tendons are tensioned first, and then the two sides are tensioned synchronously. Grouting shall be carried out in time after each tendon is tensioned, and restore the cut off ordinary reinforcement by welding during anchor sealing.

The construction process of bent cap shall in strict accordance with the requirements of design documents, and the concrete strength of bent cap and the tension of prestressed steel strand shall meet the design requirements.

\section{Inversion analysis of the construction process of bent cap}

According to calculation, the bending and shear resistance capacity of the original design of the bent cap meet the requirements of the design code; the crack resistance of normal section and inclined section of bent cap can meet the requirements of design code in the normal service limit state of the endurance condition. However, there is no analysis on the impact of temporary 
construction load on the structural safety in the design documents. In order to analyze the causes of bent cap cracking during the construction period, a numerical calculation model for the No. 4 bent cap (pier height $50.5 \mathrm{~m}$ ) is established. Considering the temporary load of 145 tons of bridge erecting machine and 15 tons for each of the two artillery trucks, the inversion analysis and verification of the construction process are carried out.

(1) Model calculation parameters: concrete $\mathrm{T}$ beam is C50 concrete, bent cap is C50 concrete, bridge pier is C40 concrete; The pre-stressed tendon is $\phi 15.2 \mathrm{~mm}$ high-strength and low-relaxation steel strand, standard tensile strength $\mathrm{fpk}=1860 \mathrm{MPa}$, and the elastic modulus $\mathrm{EP}=1.95 \times 105 \mathrm{MPa}$.

(2) Load combination: the stress of bridge components is calculated according to the short-term condition during the construction phases such as fabrication, transportation and installation. It is adopted in accordance with the "Specifications for Design of Highway Reinforced Concrete and Prestressed Concrete Bridges and Culverts" (JTG D62-2004).

(3) Construction stage: The construction stage is divided into 14 construction stages as shown in Figure 4 during calculation, in which the girder body is erected in the order of 4, 3, 5, 2, 6, 1 and 7, as shown in Figure 5. In the process of erecting T-beam by the bridge erector, T-beam can move along the longitudinal and transverse bridge directions as shown in Figure 6.

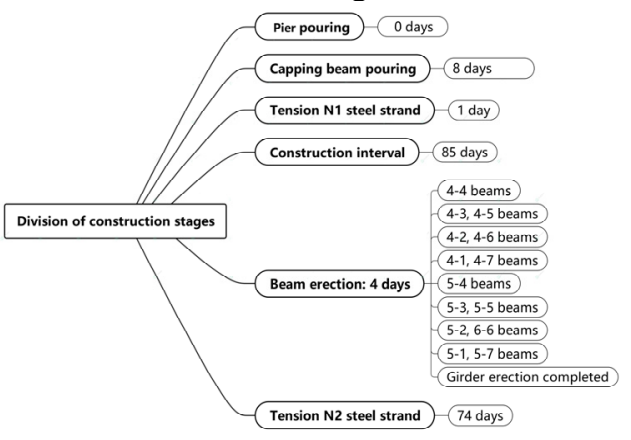

Figure 4 Division of construction stages

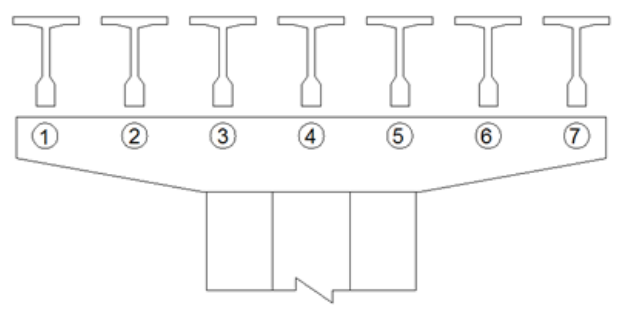

Fig. 5 Bridge girder numbering diagram

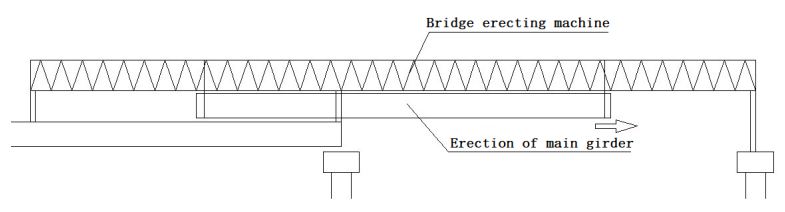

Fig. 6 Schematic diagram of $\mathrm{T}$ beam erection by bridge erector

(4) Calculation results: the calculation results are shown in Figure 7and Figure 8. It can be seen from the figure that the maximum tensile stress of normal section on the top edge of bent cap pier top section is 4.70MP when 5-1 \# and 5-7 \# beams are erected in construction stage 12 .

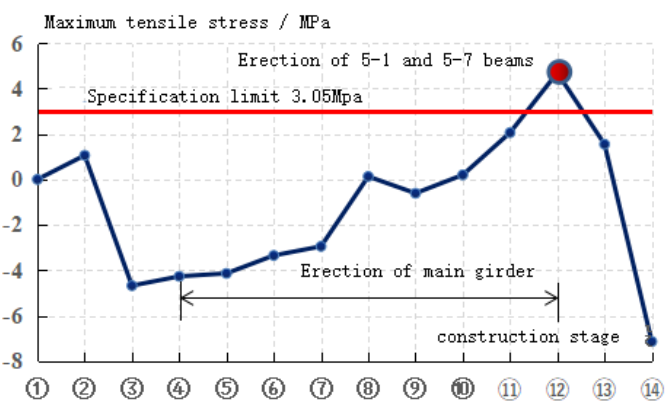

Figure7 Maximum tensile stress of top edge of bent cap pier top section

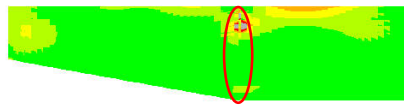

a) Side

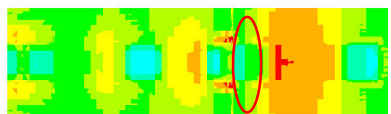

b) Top surface
Figure 8 Main tensile stress of bent cap

Based on the above analysis, it is considered that after considering the temporary load during the construction period, under the most unfavorable condition of T-beam installation and erection, the maximum normal cross-sectional tensile stress on the top edge of the top section of the bent cap pier reaches $4.70 \mathrm{MP}$, which has exceeded the specification limit of $3.05 \mathrm{MPa}$, cracks appear in the cross section of the bent cap pier top and the root of the cantilever. The calculation results are consistent with the actual bridge test results, indicating that the construction temporary load has a greater influence on the mechanical performance of bent cap.

\section{Analysis of the influence of cracks on later use}

The lateral vertical cracks at the root of the cantilever of the bent cap and the "L"-shaped cracks connecting the side and the top are the negative moment bending cracks under the most unfavorable construction load. The anatomy of $11 \#$ bent cap reveals that the cracked area along the width direction of the bent cap has accounted for more than $2 / 3$, and the cracked area along the height direction of the bent cap has accounted for more than $1 / 2$. Compared with the theoretical calculation, the width and height of the compression area of the structure are greatly reduced, which will have the following effects on the structure: After the bent cap is cracked, the internal force of the cross section is redistributed, the area of the concrete in the compression zone of the cracked section is reduced, the shear resistance section is reduced, stress concentration is formed, resulting in stress concentration and greater loss of bearing capacity. After the bridge being put into operation, the live load may lead to further increase of crack development, aggravation of crack degree and even damage. 
Based on the investigation results of the cracking status of the bent cap, the shear bearing capacity and shear section of the cracked bent cap are checked, and the residual section is calculated as shown in Figure 9.

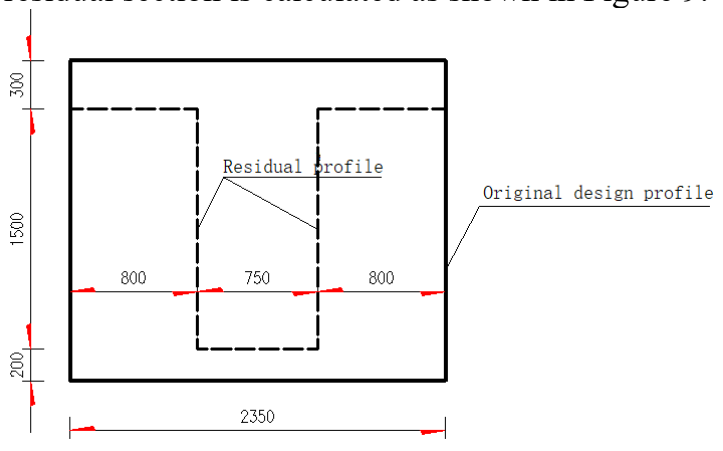

Figure 9 Calculation of residual section of bent cap

The load effect of the shear bearing capacity of the control section of the bent cap (the root section of the outer cantilever of the bent cap) is $12556.6 \mathrm{kN}$, and the bearing capacity is $3433.4 \mathrm{kN}$; The load effect of the shear section of the control section (the root section of the outer cantilever of the bent cap) is $12556.6 \mathrm{kN}$, and the bearing capacity of the shear section is $4192.3 \mathrm{kN}$. The bearing capacity of the residual section and the shear section of the bent cap do not meet the requirements of the code. If the glue injection method is considered to repair the original concrete section, the effective bonding depth should reach $63 \mathrm{~cm}$. It means that the width of the section involved in the force should be at least $2000 \mathrm{~mm}$.

\section{Maintenance and reinforcement treatment scheme}

The upper and lower edge stresses of the outer cantilever root section of the bent cap meet the design requirements according to the original design state and the most unfavorable load combination. Therefore, the stress level of the concrete in the existing core section of the cracked section can be reduced by unloading (lifting and unloading the side beam and secondary side beam), and then the cracking section of the bent cap can be restored by gluing the cracks. In view of the particularity of the project, the gluing scheme should be confirmed and optimized through the process test, and the gluing scheme should be confirmed and optimized through the process test, so as to achieve the maximum bonding of the fracture surface in the basically stress free state, so as to determine the effective section area of the bent cap after gluing. The specific construction process and key points are shown in Figure 10, and the layout of lifting and unloading scheme is shown in Figure 11.

The upper and lower edge stresses of the cantilever root section of the outer cantilever of the combined cover beam meet the design requirements, so the cracking can be reduced by unloading (the side beam and the secondary side beam are jacked and unloaded). The stress level of the concrete in the existing core section area of the cross-section, then the cracks are glued to restore the cracked section of the cap beam, and then the top is unloaded and restored. In view of the particularity of this project, the gluing plan should be confirmed and optimized through the process test, and the gluing scheme should be confirmed and optimized through the process test, so as to achieve the maximum degree of bonding the fractured surfaces together in a basically stress-free state to determine the adhesion The effective cross-sectional area of the rear cover beam. The specific construction process and main points are shown in Figure 10 , and the layout of the lifting and unloading scheme is shown in Figure 11.

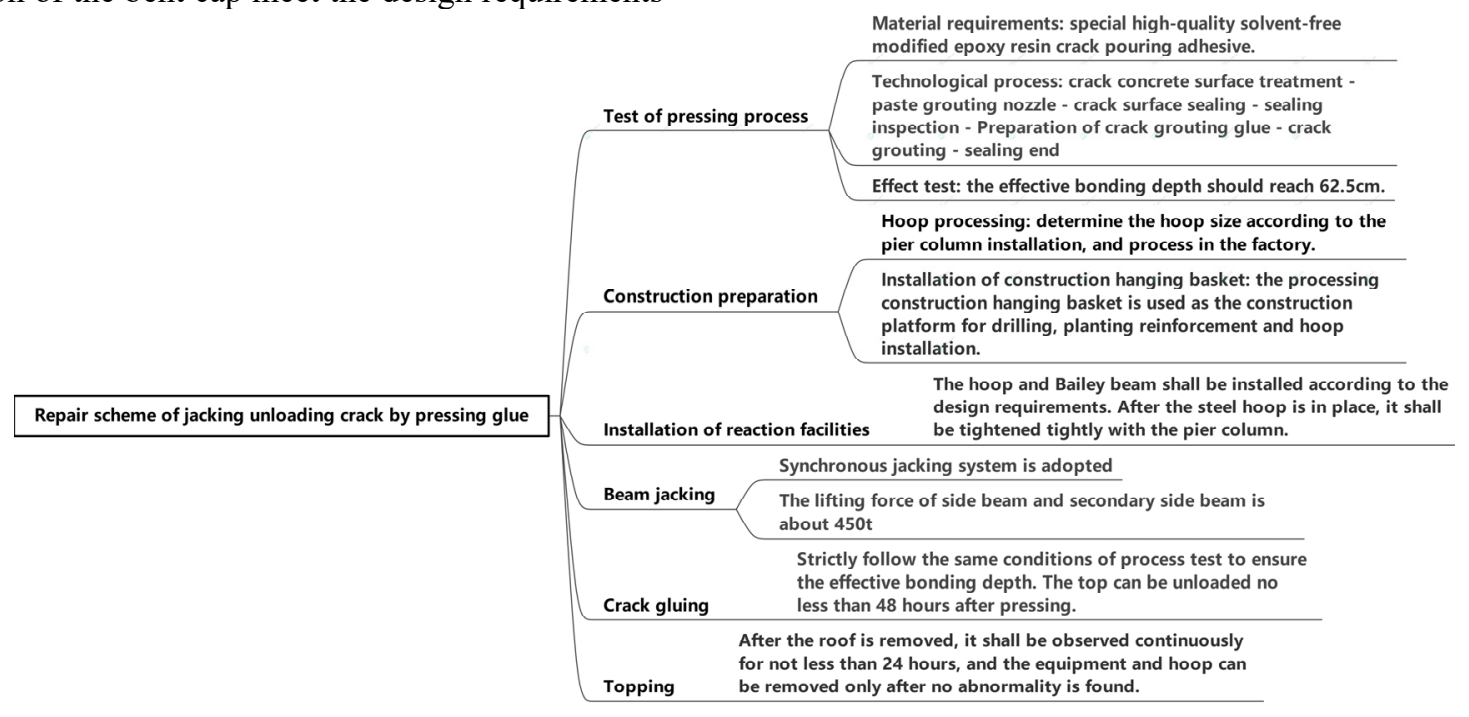

Fig. 10 Process and construction key points of jacking and unloading combined with pressure glue scheme of similar bridges. 


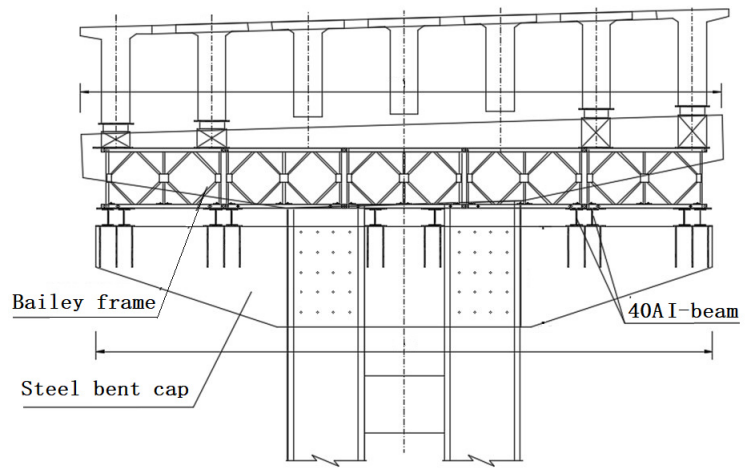

Figure11 Layout of jacking and unloading scheme

\section{Conclusion}

Based on the investigation of crack pattern, construction data and numerical simulation calculation of a bridge's pre-stressed bent cap, this paper analyzed the crack causes of the bent cap and the influence of the crack on the later use function, and put forward the repair plan of jacking and unloading combined with pressure glue, which realized the successful reinforcement and reconstruction of the bent cap crack. The technical ideas and reinforcement methods in this paper can provide reference for disease diagnosis and treatment

\section{References}

1. General Code for the Design of Highway Bridges and Culverts (JTJ D60-2004).

2. Code for Design of Highway Reinforced Concrete and Prestressed Concrete Bridge and Culvert (JTG D62-2004).

3. Zhao Xiaoyan, Wang Chen. Standardized reinforcement technique of vertical cracking of double-column reinforced concrete cover beam. Highway Traffic Technology (Applied Technology), 28.2012 (09): 259-262

4. Cen Guangfeng, Du Bin, Li Qi. cracking load of double column pier. China Water Transport, 2020 (12): 104-105

5. Zhang Xiaobin, Zhao Qi. The cracking mechanism of double cantilever concrete cover girder. Highway, 2014 (04): 104-107

6. Wu Lixin, Li Song, Tang Ying. Discussion on the bridge cracking of reinforced concrete T-shaped pier cover, Railway Building, 2015 (05): 9-11 